\title{
Lipoprotein(a), apolipoprotein(a) polymorphism and coronary artery disease severity in type 2 diabetic Tunisian population
}

\author{
Abid Kaouthar'*, Mili Donia ${ }^{1}$, Trabelsi Imen ${ }^{2}$, Msolli Mohamed Amine ${ }^{3}$, Nouira Semir ${ }^{3}$ and Kenani Abderraouf ${ }^{1}$ \\ ${ }^{1}$ Laboratory of biochemistry, UR 12ES08, Faculty of Medicine, Monastir, Tunisia \\ ${ }^{2}$ Research Unit, UR 12ES09 Dyslipidemia and Atherogenesis, Faculty of Medicine, Monastir, Tunisia \\ ${ }^{3}$ Emergency Medicine, F. Bourguiba University Hospital, Monastir, Tunisia
}

\begin{abstract}
Background: Lipoprotein (a) $[\mathrm{Lp}(\mathrm{a})]$ is an important genetic risk factor for coronary artery disease (CAD), but there is not enough data in the literature about the association between $\mathrm{Lp}(\mathrm{a})$ levels and the severity of CAD in diabetic patients. In addition to that, no studies considered to the role of apo(a) polymorphism. The aim of theis study was to investigate the association of the severity of coronary atherosclerosis with Lp(a) levels and apo(a) polymorphism in a type 2 diabetic Tunisian population.

Methods: The study population consisted of 238 consecutive type 2 diabetic patients undergoing a routine coronary angiography. The patients were subdivided into four subgroups according to the number of coronary arteries diseased: normal arteries $(n=30)$, single-vessels $(n=75)$, two-vessels $(n=55)$ and multi-vessels $(n=78)$.

Results: Lp(a) levels (normal arteries: $15.8 \pm 20.1 \mathrm{mg} / \mathrm{dl}$; mono-vessel disease: $20.1 \pm 15.9 \mathrm{mg} / \mathrm{dl}$; bi-vessel disease: $20.2 \pm 15.4 \mathrm{mg} / \mathrm{dl}$; multivessel disease: $28.3 \pm 17.2$ $\mathrm{mg} / \mathrm{dl} ; \mathrm{p}<0.001$ ) and the percentages of patients with at least one isoform of low molecular weight (normal arteries: $25.2 \%$; mono-vessel disease: $39.0 \%$; bi-vessel disease: $76.8 \%$; multi-vessel disease: $85.3 \% ; \mathrm{p}<0.001$ ) were significantly associated with increasing number of coronary vessels diseased. Multiple logistic regression analysis showed that both $\mathrm{Lp}$ (a) levels (OR: 1.30; 95\% CI: 1.12-4.10) and apo(a) polymorphism (OR: 3.63; 95\% CI: 1.78-6.45) were independent predictors of CAD severity.
\end{abstract}

Conclusions: This study demonstrated that $\mathrm{Lp}$ (a) levels and apo(a) polymorphism are strong predictors of CAD severity in a type 2 diabetic Tunisian population.

\section{Introduction}

Lipoprotein (a) (Lp[a]) is composed of a low-density lipoprotein (LDL) particle and a glycoprotein molecule known as apolipoprotein(a) [apo(a)] [1]. Apolipoprotein(a) is characterized by a high degree of genetic polymorphism, with many isoforms in plasma [2,3]. In advanced atherosclerosis, Lp (a) is an independent risk factor not dependent on LDL. Lp (a) represents a coagulant risk of plaque thrombosis [4]. Few studies have analyzed the possible role of apo(a) polymorphism in relation to the severity of coronary atherosclerosis [5]. Several investigations show an independent association of Lipoprotein(a), homocysteine and apo( a) polymorphism with silent CAD [6-9]. Other studies are needed to establish whether these parameters are suitable for CAD screening in diabetic patients.

The purpose of this study was to investigate the association of the severity of coronary artery disease not only with $\mathrm{Lp}$ (a) levels but also with apo(a) polymorphism in a type 2 diabetic Tunisian population.

\section{Methods}

\section{Patients}

The study population consisted of 238 consecutive type 2 diabetic patients undergoing a routine coronary angiography to evaluate chest pain or suspected CAD. Patients with personal history of CAD were excluded. Other exclusion criteria were: age $<45$ or $>70$ years, duration of diabetes $<1$ year, cardiomyopathy, heart failure, history of artery revascularization, renal insufficiency (serum creatinine $\geq 130$ Amol/l), proteinuria, alcoholism, neoplasia, pregnancy, liver and endocrine diseases. All patients were Tunisian and gave their informed consent to participate in the study. The study protocol conforms to the ethical guidelines of the 1975 Declaration of Helsinky. Diabetic subjects were defined by a fasting plasma glucose $>7.0 \mathrm{mmol} / \mathrm{L}$, or by the use of anti-diabetic drugs [10]. Hypertension was diagnosed as a blood pressure of higher than 140/90 $\mathrm{mmHg}$, which was measured according to guidelines [11] and/or the current use of anti-hypertensive drugs. Patients with albumin excretion rate (AER) $<30 \mathrm{mg} /$ day were considered normoalbuminuric; patients with AER between 30 and 299 $\mathrm{mg}$ /day were considered microalbuminuric.

\section{Biochemical analysis}

Venous blood samples were taken from subjects after fasting for

Correspondence to: Abid Kaouthar, Laboratory of biochemistry, UR 12ES08, Faculty of Medicine, Monastir, Tunisia, Tel: 0021673462 200, Fax: 0021673 460 737, E-mail: kaouthar_abid@yahoo.fr

Key words: lipoprotein(a), apolipoprotein(a), coronary artery disease, type 2 diabetes

Received: August 15, 2016; Accepted: August 29, 2016; Published: August 31, 2016 
$12 \mathrm{~h}$. For the quantification of $\mathrm{Lp}(\mathrm{a})$ and the characterization of apo(a) isoforms we used plasma obtained by addition of EDTA and low speed centrifugation at $4^{\circ} \mathrm{C}$ for $12 \mathrm{~min}$. Immediately after centrifugation, plasma samples were frozen and stored at $\_80$-C. Cholesterol, HDL and triglycerides were determined at accredited clinical laboratories using routine clinical methods.. LDL was calculated by Friedewald's formula, considering the contribution of $\mathrm{Lp}(\mathrm{a})$ on LDL levels [12]. Glycated haemoglobin (HbAlc) was measured by a high-performance liquid chromatography (Biorad, Richmond, CA). Apo(a) isoforms were detected by a high-resolution immunoblotting technique [6,7].

\section{Severity of coronary artery disease}

All patients recruted in the study were subjected to coronary angiography, performed using the Sones technique with filming of multiple views of each vessel [13]. Subjects were defined with coronary artery disease (CAD) when presenting a stenosis $>50 \%$ in at least one major coronary artery. Subjects were defined without coronary artery disease (No CAD) when presenting a stenosis $<50$ in at least one major coronary artery. The severity and the extent of coronary artery disease were evaluated with the Gensini score [14]. The Gensini score was computed by assigning a severity score to each coronary stenosis according to the degree of luminal narrowing and its geographic importance [15]. The diabetic patients were divided into four subgroups on the basis of stenotic major coronary arteries. Moreover, the results of quantitative coronary angiography have also been expressed according to the Gensini scoring system [14]. Patients with significant coronary disease were also subdivided into two subgroups with a Gensini score $>40$ or with a Gensini score $\leq 40$. In patients who have undergone PTCA or aorto-coronary bypass surgery, the angiographic severity was measured before the revascularization procedures.

\section{Statistical analysis}

By using an analysis of covariance, all data regarding lipid parameters were adjusted for sex, BMI, smoking, drug intake, and presence of hypertension, microalbuminuria and menopause. To assess differences in cholesterol, LDL, HDL, BMI, the analysis of variance was utilized. Because of the highly "skewed" distribution of Lp(a) and triglycerides levels, to compare $\operatorname{Lp}(\mathrm{a})$ and triglycerides values the Kruskall-Wallis test was used. The Pearson chi-squared test was exploited for frequency comparison. A multiple logistic regression analysis with the presence of CAD severity (Gensini score $>$ or $\leq 40$ ) as the dependent variable was performed. Odds Ratios (ORs) were estimated and the results were given as ORs and $95 \%$ CI. Data were presented as means \pm S.D., unless otherwise stated. $\mathrm{p}<0.05$ was considered significant.

\section{Results}

Clinical and biological features of the whole study population and of subgroups with 0 , single-, two-, and multi-vessel stenosis

As shown on table 1, there is a significant linear increase in the percentages of males and subjects with a family history for CAD and in BMI. No significant differences in age, diabetes duration and glycemic control were found among the subgroups. Lp(a) levels and the percentages of patients with at least one isoform of low molecular weight (MW) were significantly correlated with increasing number of coronary vessels diseased.

\section{Clinical and biological features of the whole study population and of diabetic patients with normal arteries, CAD patients with Gensini score $<\mathbf{4 0}$ and those with Gensini score $>\mathbf{4 0}$}

As shown on table 2, there is a significant linear increase in the percentages of males and subjects with a family history for CAD, in cholesterol and LDL levels. No significant differences in age, diabetes duration and glycemic control were found among all the subgroups. $\mathrm{Lp}$ (a) levels and the percentages of patients with at least one isoform of low MW were significantly correlated with the increasing extent of the CAD.

\section{Multivariable analysis}

A multiple logistic regression analysis was performed with CAD severity (Gensini score $\leq$ or $>40$ ) as the dependent variable and the following as predictive variables: gender, age, family history of $\mathrm{CAD}$, hypertension, diabetes duration, smoking, microalbuminuria, HbAlc, BMI, Lp(a), cholesterol, triglycerides, LDL, HDL, statin therapy. Analysis showed that BMI (OR: 2.17; 95\% CI: 1.27-3.88; $\mathrm{p}=0.04$ ), cholesterol levels (OR: 2.52; 95\% CI: 0.95-4.78; $\mathrm{p}=0.031$ ), Lp(a) levels (OR: 1.40; 95\% CI: 0.82-4.44; $\mathrm{p}=0.04$ ) and family history of CAD (OR: 1.88; 95\% CI: $1.20-2.16 ; \mathrm{p}=0.037$ ) were significant predictors of CAD severity in diabetic patients. When apo(a) phenotypes (presence of at least one isoform of low MW/presence of only isoforms of high MW) were added to the list of potential predictors, the analysis showed that apo(a) polymorphism (OR: 3.33; 95\% CI: 1.53-6.44; $\mathrm{p}=0.001$ ), BMI

Table 1. Clinical and biological features of the whole study population and of subgroups with 0 , single-, two-, and multi-vessel stenosis.

\begin{tabular}{|c|c|c|c|c|c|c|}
\hline & Total & NO. stenosis & Single-vessel & Two-vessels & Multi-vessels & p \\
\hline $\mathrm{N}$ & 238 & 30 & 75 & 55 & 78 & \\
\hline Gender $(\mathrm{M} / \mathrm{F})$ & $175 / 63$ & $16 / 14$ & $55 / 20$ & $45 / 10$ & $63 / 15$ & $<0.01$ \\
\hline Age (years) & $57.2 \pm 6.8$ & $56.1 \pm 6.5$ & $57.0 \pm 6.7$ & $59.1 \pm 7.1$ & $57.6 \pm 6.9$ & Ns \\
\hline Family history of CAD & 28.2 & 9.5 & 15.6 & 28.9 & 44.9 & $<0.001$ \\
\hline Hypertension & 44.5 & 42.9 & 32.9 & 51.1 & 48.3 & $<0.05$ \\
\hline BMI & $27.1 \pm 3.1$ & $27.4 \pm 3.5$ & $26.6 \pm 2.5$ & $28.2 \pm 2.6$ & $26.5 \pm 2.9$ & 0.006 \\
\hline Diabetes duration (years) & $8.1 \pm 5.2$ & $7.6 \pm 4.3$ & $6.7 \pm 5.2$ & $9.2 \pm 7.1$ & $8.0 \pm 5.9$ & Ns \\
\hline $\mathrm{HbAlc}(\%)$ & $7.3 \pm 1.6$ & $7.1 \pm 1.1$ & $7.9 \pm 1.9$ & $7.3 \pm 1.6$ & $7.3 \pm 1.6$ & Ns \\
\hline Microalbuminuria (\%) & 38.9 & 8.9 & 45.9 & 61.1 & 34.6 & $<0.001$ \\
\hline Smoking (\%) & 71 & 35.7 & 73.1 & 68.0 & 79.6 & 0.004 \\
\hline Cholesterol (mmol/l) & $5.6 \pm 1.3$ & $5.1 \pm 0.6$ & $5.3 \pm 0.8$ & $6.1 \pm 1.0$ & $6.1 \pm 1.0$ & Ns \\
\hline $\mathrm{LDL}(\mathrm{mmol} / \mathrm{l})$ & $4.2 \pm 1$ & $3.9 \pm 0.9$ & $3.7 \pm 0.8$ & $4.3 \pm 0.9$ & $4.3 \pm 0.9$ & Ns \\
\hline $\operatorname{HDL}(\mathrm{mmol} / \mathrm{l})$ & $1.4 \pm 0.2$ & $1.1 \pm 0.1$ & $1.0 \pm 0.2$ & $1.2 \pm 0.1$ & $1.4 \pm 0.3$ & Ns \\
\hline Triglycerides (mmol/l) & $2.1 \pm 0.8$ & $1.9 \pm 0.7$ & $2.3 \pm 1.3$ & $1.9 \pm 0.8$ & $2.1 \pm 0.9$ & Ns \\
\hline \multicolumn{7}{|l|}{$\mathrm{Lp}(\mathrm{a})(\mathrm{mg} / \mathrm{dl})$} \\
\hline Mean & $23.3 \pm 17.3$ & $15.8 \pm 20.1$ & $20.1 \pm 15.9$ & $20.2 \pm 15.4$ & $28.3 \pm 17.2$ & $<0.001$ \\
\hline Median & 18.5 & 7.1 & 13.1 & 18.6 & 28.5 & \\
\hline Range & $0.5-78$ & $0.5-78$ & $1.1-61.9$ & $0.5-61$ & $0.5-61.1$ & \\
\hline Low apo(a) phenotypes (\%) & 61.2 & 25.2 & 39.0 & 76.8 & 85.3 & $<0.001$ \\
\hline statins & 35.3 & 39.0 & 36.7 & 32.6 & 30.6 & Ns \\
\hline
\end{tabular}


Table 2. Clinical and biological features of the whole study population and of diabetic patients with normal arteries, CAD patients with Gensini score $<40$ and those with Gensini score $>40$.

\begin{tabular}{|c|c|c|c|c|c|}
\hline & Total & NO. stenosis & Gensini score $<\mathbf{4 0}$ & Gensini score $>\mathbf{4 0}$ & $\mathbf{p}$ \\
\hline $\mathrm{N}$ & 238 & 30 & 93 & 115 & \\
\hline Gender $(\mathrm{M} / \mathrm{F})$ & $175 / 63$ & $16 / 14$ & $70 / 23$ & $89 / 25$ & $<0.05$ \\
\hline Age (years) & $57.2 \pm 6.8$ & $56.1 \pm 6.5$ & $57.4 \pm 6.8$ & $58.2 \pm 6.4$ & Ns \\
\hline Family history of CAD & 28.2 & 9.5 & 27.6 & 39.1 & $<0.01$ \\
\hline Hypertension & 44.5 & 42.9 & 40.1 & 47.9 & Ns \\
\hline BMI & $27.1 \pm 3.1$ & $27.4 \pm 3.5$ & $26.9 \pm 3.2$ & $26.8 \pm 3.1$ & Ns \\
\hline Diabetes duration (years) & $8.1 \pm 5.2$ & $7.6 \pm 4.3$ & $8.5 \pm 5.8$ & $7.3 \pm 5.3$ & Ns \\
\hline HbA1c (\%) & $7.3 \pm 1.6$ & $7.1 \pm 1.1$ & $7.6 \pm 1.9$ & $7.2 \pm 1.4$ & Ns \\
\hline Microalbuminuria (\%) & 38.9 & 8.9 & 48.1 & 42.5 & $<0.005$ \\
\hline Smoking (\%) & 71 & 35.7 & 73.5 & 72.6 & $<0.001$ \\
\hline Cholesterol (mmol/1) & $5.6 \pm 1.3$ & $5.1 \pm 0.6$ & $5.6 \pm 0.9$ & $6.3 \pm 0.8$ & $<0.01$ \\
\hline $\mathrm{LDL}(\mathrm{mmol} / \mathrm{l})$ & $4.2 \pm 1$ & $3.9 \pm 0.9$ & $4.3 \pm 0.6$ & $4.4 \pm 0.9$ & $<0.01$ \\
\hline $\mathrm{HDL}(\mathrm{mmol} / \mathrm{l})$ & $1.4 \pm 0.2$ & $1.1 \pm 0.1$ & $1.0 \pm 0.2$ & $1.4 \pm 0.3$ & Ns \\
\hline Triglycerides $(\mathrm{mmol} / \mathrm{l})$ & $2.1 \pm 0.8$ & $1.9 \pm 0.7$ & $2.1 \pm 1.0$ & $1.9 \pm 1$ & Ns \\
\hline \multicolumn{6}{|l|}{$\mathrm{Lp}(\mathrm{a})(\mathrm{mg} / \mathrm{dl})$} \\
\hline Mean & $23.3 \pm 17.3$ & $15.8 \pm 20.1$ & $21.7 \pm 17.1$ & $25.3 \pm 17.1$ & $<0.01$ \\
\hline Median & 18.5 & 7.1 & 18.1 & 23.8 & \\
\hline Range & $0.5-78$ & $0.5-78$ & $0.5-63$ & $0.5-60.9$ & \\
\hline Low apo(a) phenotypes (\%) & 61.2 & 25.2 & 52.3 & 79.4 & $<0.005$ \\
\hline statins & 35.3 & 39.0 & 29.5 & 38.8 & Ns \\
\hline
\end{tabular}

(OR: 2.23; 95\% CI: 1.19-4.59; $\mathrm{p}=0.015)$ and cholesterol levels (OR: 2.72; 95\% CI: 1.13-5.58; $\mathrm{p}=0.039)$ were independent predictors of CAD severity in type 2 diabetes mellitus. $\operatorname{Lp}(\mathrm{a})$ levels $(\mathrm{p}=0.67)$ and family history of CAD (0.082) are not significant.

\section{Discussion}

Few studies are available in the literature on the association between Lp(a) levels and the severity of coronary atherosclerosis in diabetic patients [16-18]. A study of Gazzaruso et al. shows that high Lp(a) levels and apo(a) phenotypes of low MW are associated with silent CAD not only in diabetic patients with normal ECG but also in those with ECG abnormalities [7]. Their study confirms that microalbuminuria and smoking may predict silent CAD in people with diabetes and shows an independent association between low HDL levels and silent CAD [7].

Association studies have related $\mathrm{Lp}(\mathrm{a})$ plasma levels or apo(a) isoform size (defined by immunoblotting) to the risk for CHD, myocardial infarction, stroke, or peripheral vascular disease. With only a few exceptions [19], all published retrospective case-control studies report an association of high $\mathrm{Lp}$ (a) with atherosclerotic vascular disease $[20,21]$.

A previous study of Gazzaruzo and al. showed that in the general population $\mathrm{Lp}(\mathrm{a})$ levels were not associated with CAD severity, while apo(a) phenotypes strongly predicted the degree of coronary atherosclerosis [5]. This study shows that both Lp(a) levels and apo(a) polymorphism are associated with CAD severity; they also found that the predictive power of apo(a) polymorphism was greater than that of $\mathrm{Lp}$ (a) levels. The difference in the strength of the association of $\mathrm{Lp}(\mathrm{a})$ levels with CAD extent between another study of the same team [13] and the study that we are talking about may be simply due to the fact that the first study analysed the general population, while the second one evaluated diabetic subjects.

The finding of the present study concerns the fact that in diabetic population apo(a) polymorphism is highly associated with CAD extent. The association between apo(a) polymorphism seems to be higher than that between $\mathrm{Lp}(\mathrm{a})$ levels and CAD extent. These results are in agreement with other studies analysing the general population [22, 23]. Other studies showed a growing evidence that apo(a) polymorphism is a strong predictor for $\mathrm{CAD}$ and that its predictive power may be greater than that of $\mathrm{Lp}(\mathrm{a})$ levels [24-26].
In conclusion, this study demonstrated that both $\mathrm{Lp}(\mathrm{a})$ levels and apo(a) phenotypes may be used not only as predictors of CAD, but also as reliable predictors of CAD severity in type 2 diabetic patients. Certainly, it is possible to suppose that diabetic subjects with a genetic predisposition to CAD due to $\mathrm{Lp}(\mathrm{a})$ and apo(a) polymorphism may have an earlier and more accelerated coronary atherosclerosis.

\section{References}

1. Marcovina SM, Koschinsky ML (1998) Lipoprotein(a) as a risk factor for coronary artery disease. Am J Cardiol 82: 57U-66U. [Crossref]

2. Kamboh MI, Ferrell RE, Kottke BA (1991) Expressed hypervariable polymorphism of apolipoprotein (a). Am J Hum Genet 49: 1063-1074. [Crossref]

3. Marcovina SM, Zhang ZH, Gaur VP, Albers JJ (1993) Identification of 34 apolipoprotein(a) isoforms: differential expression of apolipoprotein(a) alleles between American blacks and whites. Biochem Biophys Res Commun 191: 1192-1196. [Crossref]

4. Caplice NM, Panetta C, Peterson TE, Kleppe LS, Mueske CS, et al. (2001) Lipoprotein (a) binds and inactivates tissue factor pathway inhibitor; A novel link between lipoproteins and thrombosis. Blood 98: 2980-2987. [Crossref]

5. Gazzaruso C, Bruno R, Pujia A, De Amici E, Fratino P, et al. (2006) Lipoprotein(a), apolipoprotein(a) polymorphism and coronary atherosclerosis severity in type 2 diabetic patients. Int J Cardiol 108: 354-358. [Crossref]

6. Gazzaruso C, Garzaniti A, Giordanetti S, Falcone C, De Amici E, et al. (2002) Assessment of asymptomatic coronary artery disease in apparently uncomplicated type 2 diabetic patients: a role for lipoprotein(a) and apolipoprotein(a) polymorphism. Diabetes Care 25: 1418-1424. [Crossref]

7. Gazzaruso C1, Garzaniti A, Giordanetti S, Falcone C, Fratino P (2002) Silent coronary artery disease in type 2 diabetes mellitus: the role of Lipoprotein(a), homocysteine and apo(a) polymorphism. Cardiovasc Diabetol 1: 5. [Crossref]

8. Labudovic DD, Toseska KN, Alabakovska SB, Todorova BB (2003) Apoprotein(a) phenotypes and plasma lipoprotein(a) concentration in patients with diabetes mellitus. Clin Biochem 36: 345-551. [Crossref]

9. Gazzaruso C, Garzaniti A, Falcone C, Geroldi D, Finardi G, et al. (2001) Association of Lipoprotein(a) levels and apolipoprotein(a) phenotypes with coronary artery disease in type 2 diabetic patients and in non diabetic subjects. Diabet Med 18: 589-594. [Crossref]

10. Wang JG, Staessen JA, Franklin SS, Fagard R, Gueyffier F (2005) Systolic and diastolic blood pressure lowering as determinants of cardiovascular outcome. Hypertension 45: 907-913. [Crossref]

11. Mancia G, De Backer G, Dominiczak A, Redón J, Zanchetti A, et al. (2007) 2013 ESH/ESC Guidelines for the management of arterial hypertension: The Task Force for the Management of Arterial Hypertension of the European Society of Hypertension (ESH) and of the European Society of Cardiology (ESC). J Hypertens 25: 1105-1187. [Crossref] 
12. Li KM, Wilcken DE, Dudman NP (1994) Effect of serum lipoprotein(a) on estimation of low-density lipoprotein cholesterol by the Friedewald formula. Clin Chem 40: 571573. [Crossref]

13. Gazzaruso C, Geroldi D, Garzaniti A, Falcone C, Fratino P, et al. (1998) Apolipoprotein(a) phenotypes as genetic markers of coronary atherosclerosis severity. Int J Cardiol 64 : 277-284. [Crossref]

14. Gensini GG (1983) A more meaningful scoring system for determining the severity of coronary heart disease. Am J Cardiol 51: 606. [Crossref]

15. Abid K, Mili D, Kenani A (2015) Polymorphism on Chromosome 9p21.3 Is Associated with Severity and Early-Onset CAD in Type 2 Diabetic Tunisian Population. Dis Markers: 792679. [Crossref]

16. Watts G, Gwilym RMAP, Mazurkiewicz J, Coltard J (1995) Independent correlation between plasma lipoprotein(a) and angiographic coronary artery disease in NIDDM. Diabetes Care 18: 234-236. [Crossref]

17. Okada E, Oida K, Tada H, Asazuma K, Eguchi K, et al. (1999) Hyperhomocysteinemia is a risk factor for coronary arteriosclerosis in Japanese patients with type 2 diabetes. Diabetes Care 22: 484-490. [Crossref]

18. Pedreno J, Fernandez R, Ballester A, Jornet A, Uson M, et al. (2000) Lack of association of serum lipoproetein(a) levels with type 2 diabetes mellitus in patients with angiographically defined coronary artery disease. Int J Cardiol 74: 159-167.

19. Nieminen MS, Mattila KJ, Aaltosetala K, Kuusi T, Kontula K, et al. (1992) Lipoproteins and their genetic variation in subjects with and without angiographically verified coronary artery disease. Arterioscler Thromb 12: 58-69. [Crossref]

20. Utermann G (1989) The mysteries of lipoprotein(a). Science 246: 904-910. [Crossref]

21. Utermann G (1995) Lipoprotein(a). In: Scriver CR, Beaudet AL, Sly WS, Valle D, eds. The Metabolic and Molecular Bases of Inherited Disease. New York, NY: McGraw Hill Inc: $1887-1912$.

22. Amemija H, Arinami T, Kikuchi S, Yamakawa-Kobayashi K, Li L, et al. (1996) Apolipoprotein(a) size and pentanucleotide repeat polymorphisms are associated with the degree of atherosclerosis in coronary heart disease. Atherosclerosis 123: 181-191. [Crossref]

23. Ducas J, Silversides C, Dembinski TC, Chan MC, Tate R, et al. (2002) Apolipoprotein(a) phenotypes predict the severity of coronary artery stenosis. Clin Invest Med 25: 74-82. [Crossref]

24. Kraft HG, Lingenhel A, Köchl S, Hoppichler F, Kronenberg F, et al. (1996) Apolipoprotein(a) kringle IV repeat number predicts risk for coronary heart disease. Arterioscler Thromb Vasc Biol 16: 713-719. [Crossref]

25. Kronenberg F, Neyer U, Lhotta K, Trenkwalder E, Auinger M, et al. (1990) The low molecular weight apo(a) phenotype is an independent risk factor for coronary artery disease in hemodialysis patients: a prospective follow-up. J Am Soc Nephrol 10: 10271036. [Crossref]

26. Paultre F, Pearson TA, Weil HF, Tuck CH, Myerson M, et al (2000) High levels of $\mathrm{Lp}$ (a) with a small apo(a) isoform are associated with coronary artery disease in African American and white men. Arterioscler Thromb Vasc Biol 20: 2619-2624. [Crossref]

Copyright: ( 2016 Kaouthar A. This is an open-access article distributed under the terms of the Creative Commons Attribution License, which permits unrestricted use, distribution, and reproduction in any medium, provided the original author and source are credited. 